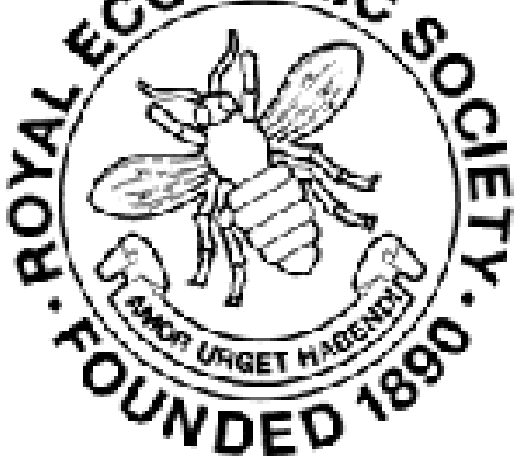

On Absolute Price, and Index Numbers of Price

Author(s): R. A. Lehfeldt

Source: The Economic Journal, Vol. 28, No. 109 (Mar., 1918), pp. 107-111

Published by: Wiley on behalf of the Royal Economic Society

Stable URL: http://www.jstor.org/stable/2222126

Accessed: 27-06-2016 02:44 UTC

Your use of the JSTOR archive indicates your acceptance of the Terms \& Conditions of Use, available at

http://about.jstor.org/terms

JSTOR is a not-for-profit service that helps scholars, researchers, and students discover, use, and build upon a wide range of content in a trusted digital archive. We use information technology and tools to increase productivity and facilitate new forms of scholarship. For more information about JSTOR, please contact support@jstor.org.

Royal Economic Society, Wiley are collaborating with JSTOR to digitize, preserve and extend access to The Economic Journal 


\section{ON ABSOLUTE PRICE, AND INDEX NUMBERS OF PRICE.}

I.

IT is a truism that there cannot be a simultaneous rise in all values : and it is equally obvious, after a moment's thinking, that there cannot even be rises in the value of some commodities which prevail in magnitude over the falls in others, for that would mean a rise in the average value. If such a state of things appears to exist, it implies that values have not been accurately measured; and this again is referable to the want of a proper standard of value.

To arrive at a proper standard we proceed as follows :Let the person $a$ possess a quantity $\alpha_{1}$ of a certain commodity.

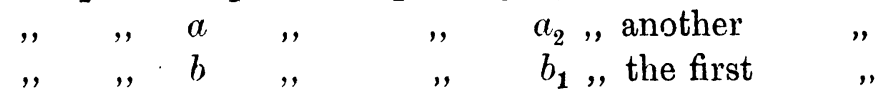

and so on. And let the prices of these commodities, in terms of any standard, be $p_{1}, p_{2}$, etc.

So that the wealth of the person $a$ is

$$
W_{a}=p_{1} a_{1}+\cdot p_{2} a_{2}+\ldots=\Sigma p a
$$

Then the total amount of the first commodity is

$$
Q_{1}=a_{1}+b_{1}+\ldots
$$

and the total wealth of the community is

$$
W=p_{1} Q_{1}+p_{2} Q_{2}+\ldots=\Sigma p Q
$$

Now suppose that while the goods in existence remain the same as before, the subjective valuation of them by the people changes, for any reason; so that the price of the first commodity, in terms of the same standard as before, becomes $p_{1}+\delta p_{1}$ and so on.

Then the increase in the total wealth of the community is

$$
\delta W=Q_{1} \delta p_{1}+Q_{2} \delta p_{2}+\ldots=\Sigma Q \delta p .
$$

Now in general this increase, being expressed in terms of an arbitrary standard (say for brevity, gold) will not be zero. But it seems to accord with the essential meaning of the term "value" that such a subjective revaluation as we have supposed should not imply a change in total wealth, but that any gain in value of some commodities is necessarily at the expense of a loss by others, such that the total is unchanged. Adopting this view, we require a new standard to which gold prices must be reduced, and we shall give to this the designation "absolute," and obtain Definition (1) 
"Absolute price is price expressed in terms of a standard such that a revaluation of commodities, unaccompanied by any change in their amount, causes no change in the total of wealth."

Then let $g$ be the price of gold in terms of the absolute standard, and the absolute price of any commodity be

Then

$$
\pi=g p
$$

$$
\delta \Sigma \pi Q=0=\delta \Sigma g p Q
$$

or

whence

$$
g \Sigma Q \delta p+\Sigma p Q \cdot \delta g=0
$$

$$
\frac{\delta g}{g}=-\frac{\Sigma Q \delta p}{\Sigma Q p}=-\frac{\Sigma Q \delta p}{W} \text {. . . . . }
$$

This equation enables us to express the fluctuations in the absolute price of gold, and consequently to realise the absolute standard of value (except for a constant factor, which is arbitrary and of no importance).

This definition, however, is not the only possible one, and it may be objected that when a subjective revaluation occurs, the efforts of the community will no longer be directed in the same way as before; but that insofar as the continued production of new goods is in question, the condition of unchanged production is really inconsistent with the premiss of changed values. We ought rather to suppose that production is modified to suit the new values, but that the total of productive effort remains the same as before. We then obtain Definition (2):

"Absolute price is price expressed in terms of a standard such that a revaluation of commodities, accompanied by the consequent redistribution of effort in production, the total of effort being unchanged, causes no change in the total of wealth." and

Let $g^{\prime}$ be the price of gold in terms of this new standard,

$$
\pi^{\prime}=g^{\prime} p
$$

be the price of any commodity.

Let $e_{1}$ be the elasticity of supply of the first commodity expressed in gold prices, or

$$
e_{1}=\frac{p_{1} d Q_{1}}{Q_{1} d p_{1}}
$$

Then the wealth of this kind produced under the new conditions will be $\left(p_{1}+\delta p_{1}\right)\left(Q_{1}+\delta Q_{1}\right)$ and will exceed the total under old conditions by

$$
p_{1} \delta Q_{1}+Q_{1} \delta p_{1}=\left(1+e_{1}\right) Q_{1} \delta p_{1}
$$


Similarly let $\epsilon_{1}$ be the elasticity of supply expressed in absolute prices, so that the increase in the wealth of the first kind is

$$
\left(1+\epsilon_{1}\right) Q_{1} \delta \pi_{1}
$$

and the increase in total wealth

by definition.

$$
\delta W=\Sigma(1+\epsilon) Q \delta \pi=0
$$

[For the changes in the Q's are not arbitrary, but are connected by the condition that their sum must be such as to save as much effort in some directions as is spent in others.]

But

so that

$$
\epsilon=\frac{\pi^{\prime} \delta Q}{Q \delta \pi^{\prime}}=\frac{g^{\prime} p \delta Q}{Q\left(g^{\prime} \delta p+p \delta g^{\prime}\right)}
$$

Hence

$$
\frac{e}{\epsilon}=\frac{g^{\prime} \delta p+p \delta g^{\prime}}{g^{\prime} \delta p}
$$

$$
\begin{gathered}
\delta W=\Sigma\left(1+e \frac{g^{\prime} \delta p}{g^{\prime} \delta p+p \delta g^{\prime}}\right) Q\left(p \delta g^{\prime}+g^{\prime} \delta p\right) \\
=\Sigma Q\left(g^{\prime} \delta p+p \delta g^{\prime}+e g^{\prime} \delta p\right) \\
=\Sigma Q\left\{p \delta g^{\prime}+(1+e) g^{\prime} \delta p\right\}=0
\end{gathered}
$$

Or

$$
\frac{\delta g^{\prime}}{g^{\prime}}=-\frac{\Sigma Q(1+e) \delta p}{\Sigma Q p}=-\frac{\Sigma Q(1+e) \delta p}{W} \quad \ldots
$$

The first of these definitions may be distinguished as the " capital," the second as the "income" definition of absolute price.

Subjective revaluations in nature are not abrupt, though they may be rapid (e.g., on outbreak of war); we must therefore suppose, in order to realise the first definition, that the revaluation happens in a time too short for an appreciable change in the existing stock of goods. In order to realise the second definition, it must be supposed to happen in a time too short to admit of an appreciable change in the amount of natural resources, capital, labour and enterpriser's ability in existence. The term "effort" in the definition is to be taken as including the use of the material factors available for the human effort.

If the money used by the community be not a mere means of exchange, but has value in itself, it must be counted as one of the commodities : for it, of course, $\delta p=0$.

II.

Index numbers are based on the theory that changes in the value of gold are measured inversely by changes in the weighted 
mean of gold prices. This would appear to be in accordance with equation (1); but the commodities chosen for calculating index numbers are always such as form an important part of income rather than of capital. Hence the customary index numbers while they give a workable approximation in the case of changes due to abundance or scarcity of money, do not apply correctly to such cases of revaluation as are considered above. On the other hand, the basis of index numbers is not consistent with equation (2). (Though the inconsistency, being only in the weighting, may not be important in practice.)

Any arbitrary set of changes in prices and quantities may be expressed as the sum of a change in demand (or subjective revaluation) and a change in supply (or in effort), in the foregoing. At first sight it might be thought that on allowing for the latter, the absolute price of gold might be determined by means of the change in demand.

But the equation of exchange is :-

$$
\Sigma n p Q=M V
$$

where $n$ is the number of times any piece of wealth is sold, $M$ is the amount of money, and $V$ the frequency with which it is used. Now, if the quantity and frequency of money remain the same, it is clear that a knowledge of the conditions of supply and demand alone will not enable us to calculate $\delta p$ since $n$ is unknown. Of course, if the $\delta p s$ are known historically equation (1) can be applied to find the absolute price of gold ; but if only the nature of the change in demand is known, equation (1) can only be applied in such a way as to satisfy equation (3). That is, an index number, even if it took into account all commodities, and was weighted in accordance with their quantity, would only give correctly changes in the value of gold due to monetary changes, but not those due to changes in supply and demand of commodities (i.e., if value be identified with absolute price as defined in this paper).

III.

At the beginning of the war an abrupt change in demand caused the value of most consumption goods to rise relatively to most instrumental goods (including with the latter durable consumption goods like houses). Now, the quantity of consumption goods in existence is much smaller than that of instrumental, but the value of $n$ for the former much exceeds that for the latter. Consequently, although $\Sigma n Q \delta p$ was positive, that of $\Sigma Q \delta p$ was negative, hence by (1) $\delta g$ was positive, i.e., the absolute price of 
gold rose. (Money is, of course, much in request in time of crisis.) Subsequently, monetary inflation tended to neutralise the rise in value of money, while exaggerating the rise in the gold price of consumable goods.

At a later stage the assumption of a constant stock of goods involved in equation (1) is to be replaced by the assumption underlying equation (2) of constant effort turned into new directions. Later still no doubt the total of effort was increased.

The extremely high gold price of consumption goods in the later years of the war cannot be explained in accordance with equation (3) entirely by an increase in $M$ and a decrease in $Q$. No doubt there is inflation of currency, not neutralised, in England at least, by hoarding; also the total output of goods is probably less than in peace time, despite greater effort. But it is worth while enquiring whether a decrease in $n$ is not of importance too. This comes about in two ways; a great part of the effort goes to produce a commodity-military service-that is only sold once. Secondly, the difficulties placed in the way of trade, and especially of speculation, would diminish $n$ and so tend to raise gold prices; a consequence almost ludicrously in conflict with the intentions of governments in discouraging speculation.

The phenomena observed in a commercial crisis are in many ways similar to those of the first phase of the war; commercial cycles generally afford good illustrations of the theory.

If the taxable income of the United Kingdom for the last half century ${ }^{1}$ be graphed, it will be found to show marked inequalities of progress. If the figures be reduced by means of Sauerbeck's index number the series shows almost equal irregularities in the opposite sense. The curve is made much smoother by the use of a new index number $=$ Sauerbeck's index +85 . This of course is far from showing that the new index is correct; but it may serve to show that for some purposes the usual indices like Sauerbeck's are incorrect.

Johannesburg,
June, 1917.

R. A. LEHFELDT

Extracts from German Periodicals Relating to the War.

THE Annalen des Deutschen Reiches, 1917, Nos. 1-4, gives a good analysis of the Auxiliary Service Act. The principal objects of the Act are to place supplies of labour at the disposal of the munitions industries and to set free for the Army men hitherto

1 Stamp, J. C. : British Incomes and Property, p. 318. 